\title{
Personnel as a Resource of Coal Mining Industry Development
}

\author{
Valeriy Bobrikov ${ }^{1, *}$, Nikita Ravochkin ${ }^{2}$, and Vladimir Shchennikov ${ }^{3}$ \\ ${ }^{1}$ T.F. Gorbachev Kuzbass State Technical University, 650000Vesennyaya str., 28, Kemerovo, Russian \\ Federation \\ ${ }^{2}$ Kemerovo State Agricultural Institute, 650056 Markovtseva street 5, Kemerovo, Russian Federation \\ ${ }^{3}$ Kemerovo State University, 650000, Krasnaya str. 6, Kemerovo, Russian Federation
}

\begin{abstract}
Based on the trends in social and economic spheres of public life, in particular - the education sphere and taking into account the specifics of the Russian coal industry enterprises, in this article the authors attempt to theoretically understand the training of personnel of coal enterprises. It is shown in the study that the essence of the principles of socially responsible behavior has ancient roots, while the consumer's attitude towards nature begins only in the era of Modern age. A critical analysis of continuing professional education, which in theory is the most practice-oriented to the needs of the market, is presented. Discrepancies with the world practice of personnel training in accordance with the requirements of enterprises are revealed. The difficulties accompanying the process of training the personnel of the coal industry enterprises are indicated. The authors also cite suggestions and recommendations regarding the training of personnel employed in the coal industry taking into account a multitude of factors noted in the study.
\end{abstract}

\section{Introduction}

In modern and unpredictable Russian society, the requirements for the professional training of the individual are increasing in connection with the trends observed in social and economic spheres of public life. Among them, those that can fairly be assessed in the negative modality can be singled out: protracted economic crises, permanent unemployment growth, restriction of career mobility, decline in wages, glut of the labor market by low-skilled personnel, etc. [1].

At the turn of the millennia, trends testifying to the systemic nature and the interdependence of the processes taking place in all spheres of public life have intensified. Modernization, taking place in the domestic education, led to a change in the educational paradigm: the knowledge-based approach was replaced by a competence-based one [2]. Education itself should now be able to guarantee the most complete personal, sociallyintegrated and practice-oriented result. From the point of view of orientation to objective requests for the innovation-driven economy development and an increase in the competitiveness of graduates of the system of continuing professional education itself in

\footnotetext{
${ }^{*}$ Corresponding author: nickravochkin@mail.ru
} 
general, and professional retraining programs in particular, a need to reorient the education system, taking into account public priorities and market needs, arises. Consequently, it becomes possible to provide each consumer of educational services with the opportunities for more effective participation (application of their competencies) in the field of practical/labor activities. With this approach, knowledge and competences become the main value, both of person and of society as a whole [2-3].

\section{Material and Methods}

In the modern economy, the outlines of globalization setting the single development vector and unification of business standards [4-5] are increasingly clear. Traditionally, enterprises invest in training and development of their personnel (human resources). However, it will not be superfluous to turn to the history of this issue. J.J. Phillips notes that investments in training and development of personnel at the enterprises originated at the turn of the XIX and XX centuries, and it is associated with the Industrial Revolution and the genesis of management. The subsequent development and changes were accompanied by corresponding transformations, mainly in the spheres of economy and technology [6]. The transition to an information society leads to more dynamic knowledge updating process, which forces the expansion of both the outlook and the range of professional competencies. The ideal specialist, according to modern ideas, should not only be ready to get continuing professional education, but also pay considerable attention to self-education and intellectual development, since this factor determines the economic situation and the social security of a person [7]. Earlier, the training of employees was carried out using enterprise's own resources, now the "external providers" of educational services are considered as so-called "channel" for personnel training in the interests of owners and managers of enterprises. Thus, the training of specialists engaged in the coal industry is a process of structured development of new competencies and obtaining new knowledge in order to upgrade professional skills in a certain field of activity with the help of own teachers or the organization of continuing professional education.

Due to the specificity and the inadequate problematique elaboration, the authors turned to the problem of the coal enterprise personnel training. The restructuring of the coal industry (which is now taking place in Russia) is one of the characteristic features of the country's long-term development, which directly points to the renewal and modernization of organizational and production structures. It is obvious that further development of the industry is closely connected with directions, rates and results of social and economic transformations in the country [8]. Personnel is the basis for the success of any enterprise, hence the coal industry modernization determines the logical statement of the problem of training professionals having the unique set of competencies. Indeed, in the realities of postindustrial society it is precisely from the human capital that "modernization" as the transition to a more competitive and efficient regime for the functioning of economic systems depends on.

Let us consider in more detail the opinions on personnel training and development. To make a profit is known to be the objective of any enterprise. In their study, A. Pendleton, S. Vitols, H. Gospel confirm this thesis, showing that the growth of investments in intellectual capital (which includes personnel) is the main reason for the growing gap between the market and the book value of the company [9].

In turn, J. Onkelinx, T.S. Manolova, L.F. Edelman note that personnel training and development are an essential element of industrial investment for each enterprise [10]. In addition, by encouraging the training of employees, the enterprise offers them the opportunity to increase the level of professionalism, which becomes relevant in the following conditions: 
- lack or even shortage of highly skilled personnel;

- permanent increase in the cost of labor (in a well-functioning market economy conditions);

- increasing competition, which sets the imperative of effective use of labor resources;

- multiplication of technical features and changes related to scientific and technological progress and the introduction of information technologies in the enterprise activities;

- increasing output of production, sales and services;

- increasing role of corporate social responsibility institution.

According to the author's opinion, the investments of enterprises in creation and maintenance of the personnel training system represent the sum of voluntary investments in solving future problems, mainly guaranteeing their competitiveness and compliance with world practice. We interpret personnel training as the most promising way to quickly and efficiently train personnel for the purposes and needs of an enterprise with a focus on specific technologies and accumulated potential. What is obvious is the minimization of time costs and other resources in solving new problems [11]. This is really necessary in view of the fact that, as practice shows, personnel are decreasingly marked by an excess of knowledge and, as a rule, in close connection with work, but not in accordance with the specialty obtained earlier. We emphasize that modern conditions make the personnel potential of the enterprise a competitive advantage, the effectiveness of which is determined through training. Regardless of the type of training: individual, group or collective, investment in training is winning and justified. It is likely that this will depend on the size of the enterprise and the student body. However, once again we point out the growing role of the knowledge economy, which, as noted above, implies an increase in the level of competence, the first part of the shift in emphasis of personnel on intellectual work [12].

\section{Results and discussion}

For Russian economy, the coal industry is one of the important links in energy economy. The competitive advantages of the Russian coal industry for the purpose of ensuring Russia's energy security are, first of all, the availability of huge coal reserves, as well as significant experience in its use. One of its priorities is the provision in which "the improvement of the system of professional training of personnel for the coal industry" is prescribed. The problems of the coal industry, in particular, measures to increase its productivity and profitability, are a hot topic. We note that the present period is characterized by the revival and modernization of the coal industry, which leads to the statement of the problem of qualified personnel training. At the present stage of development, the managers of the coal industry companies determine the implementation of professional competence as one of the most important purposes, in which the issue of increasing the level of skills and the need in updating, obtaining modern knowledge and skills, learn best practices and the development of modern methods of solving problems is important. We are most interested in the problem of systematic training of personnel employed in it. It is on it the solutions of personnel problems in the frame of the coal industry will depend on, because, for example, the industry prestige, the problem of attracting new personnel, and finally, the general increase in the competitiveness of enterprises in the global market depend on its competences. Contrary to actually existing today pluralism, we are convinced that in order to increase competitiveness and profitability in addition to the financial resources the coal industry must have professionally trained human capital motivated in the productive work. By this we mean people devoted to the company who understand and share its goals and values, and cast in lot with its functioning, professionally trained and aspiring to personal self-fulfillment. 
Traditionally it is considered that continuing professional education is the most effective because of its practical orientation to the needs of the client/customer, high cost and maximum compliance with the expected results. At a minimum, it is intended to provide an opportunity to manage the person's own educational paths, both for customers and for the students themselves. It is fair to assume that continuing professional education in Russia is not yet fully formed direction and involves difficulties in immersion in future activities, which makes it difficult to successfully master educational programs due to shortcomings in structured standards of professional activities and sharply subjective success category assessments, as well as the slurred prospects in job market. With such, almost market, orientation of continuing professional education organizations to customers of personnel training in the face of enterprises, the current situation is clarified.

Now let us turn to the problem of the professionalism of the educators who are directly involved in solving the problems of mastering competencies. After all, it is the professional preparedness of the educator that, undoubtedly, sets a certain level of the educational service quality, the consumer of which is the personnel of the companies. For us, this is paradoxical, at least for two reasons: the professionalism of the educator, whose theoretical comprehension is ignored today, in our opinion, guarantees the quality of the educational product, increasing the demand for it in the future. The second reason is that companies that send their personnel to master a particular program are oriented toward the brand of a continuing professional education organization, but not the professionalism of the cadre of instructors directly involved in brand building. With regard to training the personnel of the coal industry and analyzing the proposed educational services, the authors note that today educators who have experience in the coal industry, as well as having the skills necessary for the educator, are practically absent from the continuing professional education organizations. Thus, we can state that the practice-oriented training of workers in the coal industry in fact remains a kind of utopian project, but we also note that the customer's preferences are based on form rather than content. For example, on the loud name of the unreasonably costly program, which is, as a rule, an unadapted and often outdated foreign analog. Unfortunately, the jointly conducted (by the customer and the educational organization) adjustment of the implemented programs (includes assessment of the educational environment, familiarization with the applied educational technologies, assessment of the results of the educational process, etc.) with the purpose of determining the degree of satisfaction for the future trainees of the coal industry, being customary abroad, is practically absent.

Having analyzed the state of the coal industry development, we come to the conclusion: to ensure the effectiveness of training the personnel of this industry, it is necessary to create and develop mechanisms for multilateral interaction between authorities, businesses, educational institutions, scientific organizations - and this will allow taking into account the wishes of all interested parties as effectively as possible. We note that the implementation of educational programs should take place in accordance with the "Program for the Development of the Coal Industry of Russia for the period until 2030" [1]. Taking into account the fact that the educational process must be efficient and structured, it is necessary to carefully consider all the elements of the educational space at the program design stage. The educational programs, like the educational space, can have different scales, since they solve problems in a certain practical area of workers in the coal industry. Educational programs must be given, first of all, an applied orientation, which will serve the interests of increasing the efficiency and performance of social labor. This is not accidental, because there are a lot of factors at the coal industry enterprises that contribute to the achievement of the goals of professional development of a certain category of personnel set by the management. For example, they can be directed to their participation in the subsequent professional development of the personnel of the enterprise, to contribute to the 
achievement of specific economic objectives through the competent finance management. The organization of training of specialists in coal enterprises should not run counter to the concept of the development of education, which guarantees of their substantive actualization. At the same time, the authors of programs should take into account the current trends in the world level of scientific and technological knowledge, not forgetting that the main emphasis in the training of personnel should be made on the priority of interdisciplinary relations.

As proposals for training specialists of the coal industry, we note that it is advisable to expand the profiles and directions of programs; organize advanced training; develop modern approaches to internal training of personnel on a scientific basis, develop mechanisms for assessing the effectiveness of training; to achieve the use of innovative pedagogical technologies (modular, playful, health-saving) and active introduction of multimedia when working with personnel in the learning process, in order to avoid an educator stereotyping as a "talking head".

The authors believe that in the process of designing educational programs for professional retraining it is necessary to take into account:

- the qualitative level of the specialist's qualification and his socio-cultural status should be proportionally correlated with each other, mutually affecting both the development of the personal interests of the person as a whole and meeting the personnel requirements of various coal industry enterprises;

- the educational program within the framework of the coal business is built as a multifaceted functional structure that unites the competence of managers according to levels, types and functions of management.

- the implementation of the "Program for the Development of the Coal Industry of the Russian Federation for the period until 2030" provides for the use of mechanisms of publicprivate partnership, where the state concentrates its efforts on the infrastructure component and the projects to ensure a market perspective for the production output.

Summarizing, we note that the coal industry is one of the most important links in the structure of the Russian economy, the competitive advantages of which are being built up in accordance with the "Program for the Development of the Coal Industry of the Russian Federation for the Period to 2030" [1]. Thus, the study on the training of staff of companies carried out by us allows to concluding that the main and immediate problem is a long-term problem and is in the very process of organizing the interaction of customers and consumers with educational institutions of continuing professional education. An inaccurate understanding of goals and objectives leads to the fact that, unfortunately, the domestic practice shows the lack of analysis of the results of trainee's mastering the learning competences, which are overloaded with theoretical training, and the training itself is conducted not by professional practitioners, but by theoretical educators. Also, the effectiveness of the educational program mastered by the trainees subsequently suffers in the practical activities. Today, the part of the personnel employed in the industry does not always have a specialized education.

\section{Conclusion}

At present, it is impossible to ignore taking into account the requirements of specializing and professionalizing of personnel, which can be achieved, in particular, through the development of continuing professional education programs. Thus, the unified forms of training and ignoring the characteristics of the trainee body and the industry specificity will not give the necessary result for practical activities in the form of acquired competencies. The status of the personnel working in the coal industry is transformed over time: today, thanks to it, the value of the company increases, which determines the need for their 
(re)training and mastering new competencies for the adoption and implementation of nonstandard solutions in order to increase the competitiveness of the company. All of the above points to the need to create a communication model of "business - education - science" and use of effective forms of its integration. The authors believe that taking into account these conclusions contributes to the creation of prerequisites, not only for the speedy introduction of innovative educational technologies, but also will lead to the coherence between the training of personnel and the needs of progressive and accelerated economic development of the coal industry.

\section{References}

1. RF Government, On the Program for the Development of the Coal Industry of the Russian Federation for the Period up to 203 (RFG, Moscow, 2014)

2. L. Benade, M. Jackson, Transforming Education: Design \& Governance in Global Contexts (Springer, New York, 2017)

3. R. Ford, R. Meyer Procedia Manufacturing, 3, 1473-1480 (2015)

4. N. Hageback, The Mystery of Market Movements: An Archetypal Approach to Investment Forecasting and Modelling (Wiley, Chicago, 2014)

5. L. Kui-Wai, Redefining Capitalism in Global Economic Development (Academic Press, Los Angeles, 2017)

6. A. Manowska, K. T. Osadnik, M. Wyganowska, Resources Policy, 52, 192-200 (2017)

7. P. Merlevede, Talent Management: A Focus on Excellence. Managing Human Resources in a Knowledge Economy (Bookboon, London, 2014)

8. J. Onkelinx, T. S. Manolova, L. F. Edelman, Journal of International Management, 22:4, 351-364 (2016)

9. A. Pendleton, S. Vitols, H. Gospel, Financialization, New Investment Funds, and Labour: An International Comparison (Oxford University Press, Oxford, 2014)

10. J. J. Phillips, Accountability in human resource management: Techniques for Evaluating the Human Resource Function and Measuring Its Bottom-line Contribution (Butterworth-Heinemann, London, 2007)

11. D. Safina, Procedia Economics and Finance, 24, 563-567 (2015)

12. F. Webster Theories of the Information Society (Taylor \& Francis, London, 2006) 